\title{
O ROUBO DO SILÊNCIO E AS RAZÕES DA POESIA A CAMINHO: BREVES CONSIDERAÇÕES SOBRE UM POEMA DE MARCOS SISCAR
}

\author{
Diana Junkes Martha TONETO (UNAERP)
}

\begin{abstract}
RESUMO: Este texto pretende tecer alguns comentários sobre "Poesia a caminho",de Marcos Siscar, publicado em $O$ roubo do silêncio, destacando, em especial, a articulação entre o caráter metalinguístico do texto, que explora os limites entre prosa e poesia, e o lirismo memorialístico que dele emana, os quais, tensionados, engendram a poesia em ação no poema.
\end{abstract}

PALAVRAS-CHAVE: Poesia brasileira contemporânea; Marcos Siscar; Poesia a caminho.

\begin{abstract}
This article intends to discuss, briefly, the poem Poesia a caminhowritten by Marcos Siscar and published in $\mathrm{O}$ roubo do silêncio, giving emphasis to the articulation between the text's metalinguistics character, which explores the limits between prose and poetry, and the reminiscent lyrism that comes from the poetic word in action in the poem.
\end{abstract}

KEYWORDS: Brazilian contemporary poetry; Marcos Siscar; Poesia a caminho.

\section{Entre o silêncio e a memória: poesia}

O livro O roubo do silêncio, de Marcos Siscar, foi publicado em 2006. Trata-se de um livro peculiar e desafiador, que instiga o leitor a um percurso se não árduo, ao menos inquietante, em torno daquilo que as palavras revelam através da corporalidade de uma escritura mnemônica, densa e cifrada, a despeito da forte presença do cotidiano nos poemas, o que poderia sugerir simplicidade. Aliás, o simples é o que o poeta busca, como atesta o último poema do livro, "Provisão poética para os dias difíceis": "simplicidade é aquilo que se quer" (SISCAR, 2006, p.66), mas cuja fórmula não encontrará sem árduo trabalho, inclusive porque a simplicidade inerente à cotidianeidade não equivale às tensões sub-reptícias que a sobrevivência das recordações impõem ao eu-poético dos poemas. O falar das coisas simples e corriqueiras parece ser, no livro todo, um recurso para manter algo em silêncio, ou ainda: a aparente simplicidade que perpassa, de um modo geral, todos os poemas, 
silencia aspectos muito íntimos da subjetividade do eu-poético, que permanecem obliterados a despeito da clareza das imagens e dos temas corriqueiros, tais como o carrapicho, a cidade, o mar, as gaivotas e até mesmo as ervas daninhas, flores do mal que brotam já no primeiro poema do livro, exalando Baudelaire e Drummond: “[...] E no meio de ervas daninhas suo, me sujo, / concentrado como um artesão, enfurecido como um / filósofo, a extirpá-lo. Enquanto isso, suas sementes / caem no chão limpo e a terra as acolhe, hospitaleira. / Nuvens passam aos pedaços, quando me deito" (SISCAR, 2006, p.17).

A exata apreensão da leitura do cânone feita por Siscar em $O$ roubo do silêncio é, todavia, impossível, não só pela erudição do poeta, cujos referenciais escapam ao leitor, mas também porque a relação com a tradição se constrói amalgamada a imagens que sugerem alto grau de pessoalidade, de confissão, de rasura de um passado que o dia-a-dia traz à tona. De fato, o cotidiano rouba o silêncio das lembranças da persona poética pela voz da poesia, entretanto, ainda assim, no âmago de cada poema, algumas coisas ficarão sempre inaudíveis, escapando pelos vãos que a poesia não pode, com sua voz, preencher. Há, no silêncio dos textos, um movimento de sentidos daquilo que luta para sobreviver sem envelhecer, constituindo-se como marca distintiva dos poemas, veiculada pela memória discursiva e pelos arquivos da tradição e da experiência pessoal, emersos dos textos ou submersos neles.

Existe, em $O$ roubo do silêncio, um silenciamento de instâncias que parecem constituir aquilo que o poeta assume como herança e esse aspecto convoca uma leitura que explore o não-dito, que seja capaz de rastrear, nas malhas do tecido poético, ainda que sem apreender na totalidade, os ecos das vozes, das palavras, das coisas e dos fatos, herdados e marcados pela materialidade sígnica que, subversiva, irrompe dos poemas para roubar do silêncio seu direito de calar - é como se o poeta sentisse a obrigatoriedade de abrir caminho para a poesia passar ao mesmo tempo que a tenta silenciar, já que ela denuncia a historicidade de seus textos, suas lacunas, espectros e sobreviventes. A tensão entre o dito e o não-dito é recorrente na obra de Siscar, desde o seu primeiro livro chamado Não se diz e parece acentuar-se em todo $O$ roubo do silêncio. Como aponta Orlandi (2007, p.11), "há um modo de estar no silêncio que corresponde a um modo de estar no sentido"; modo de estar este que não corresponde 
simplesmente ao implícito, mas assume, no livro em questão, uma dimensão maior, a qual, pelo esforço do velamento, acaba, paradoxalmente, por desvelar-se.

Ainda bem, pois é porque a poesia permanece sempre como voz que atravessa implacavelmente o silêncio dos poemas, ao longo do livro, e é porque em torno dela a memória e as lembranças se organizam entre o dizer e o não-dizer, que podemos entrar em contato com a pregnância plástica de uma palavra poética que apela ao tátil. Sobre esse aspecto, também presente em outras obras de Siscar, confere Masé Lemos:

Siscar constrói [...] uma paisagem íntima, uma paisagem interior. O limite, a transgressão, é o lugar para voltar como quem entra e sai da experiência táctil, das mãos que tocam e afastam [...] (LEMOS, 2008, p. 6).

Essa palavra tátil revela as fraturas do sujeito poético, e é, também, sua escapatória, ou seja, a palavra poética, para usarmos as idéias de Greimas (2002), é a transformação que a vivência sensível opera no poeta, quebrando estereótipos, ferindo o cotidiano, a memória, as lembranças; ferindo o corpo e também o remorso que as histórias rememoradas sugerem, para entreabrir novas possibilidades de sentido: balóes brancos a enfeitar o céu das cidades sem sol. Como um aedo, o eupoético dos poemas evoca Mnemosine e costura vozes a sua voz, faz epéa; ainda que esse canto dissonante afaste-se daquilo que convencionalmente chama-se de epopeia, são os alísios desta que, em certa medida, sopram tensionando prosa e poesia, passado e presente, pelo roubo do silêncio que se converte em cante, em escritura, em palavra palpável, em reflexão metalinguística.

Premiada no Festival de Poesia de Goyaz (Premio Goyaz de Poesia/2006), a obra em questão está dividida em quatro partes: "Sentimento da violência", "Ficção de origem", "Balões brancos" e "Cidades sem sol". As duas primeiras partes têm onze poemas cada uma; e as duas últimas, oito poemas cada uma, simetria que pode, à primeira vista, instigar o leitor a certas viagens cabralinas, presentes, sim, em $O$ roubo do silêncio, assim como em outros momentos da obra do poeta, mas relativizadas pelas epígrafes de Rimbaud e de Drummond que devem servir de alerta: o indiscutível rigor construtivo, revelado nos poemas, submete-se a uma melancolia profunda e a um lirismo agudo (ou agônico), que juntos engendram os sentidos dos textos e obrigam uma leitura abissal, disposta a aceitar o lance de dados sugerido em cada poema pela 
orquestração dissonante de uma poesia andarilha que, sempre a caminho, instaura a luta do poeta contra o acaso, entre sons e imagens; memórias e impossibilidades; fluxo e contenção.

O jogo, como ensina Eni Orlandi (2007, p.15), é a porta de entrada do silêncio, é a ampliação da dimensão do significar. Em $O$ roubo do silêncio, o jogo começa a partir daquilo que o poeta nomeia "Prefácio sem fim", o qual, apesar do nome, tem fim e, mais do que isso, tem finalidade - atua como orientador de leitura do que seguirá, isto é, o que vem depois do prefácio é uma pulsão que impele o eu-poético a gritos "que um galo antes", numa tentativa de tecer a poesia à memória, esta sempre entrecortada pelo silêncio, ainda que este grito seja "cantar já distante" (SISCAR, 2006, p. 35). Impossível, ao ler o livro, não auscultar os passos dessa poesia, sua persistente vólucre voz, suas formas, seu corpo submerso em uma poética que a prosa tenta assediar com seus estilhaços metonímicos, mas não consegue.

O que se afirma no livro todo, a meu ver, para mais uma vez citar o último poema do livro, é sempre a necessidade e a urgência da poesia; de uma poesia que permita ao poeta lidar com a sobrevivência do cânone, o qual, em forma de espectro, mistura-se às lembranças da infância, da vida, ao temor ou desconfiança em relação à morte. Os pedaços da tradição apreensíveis no livro, desde a epígrafe até as citações explicitas do último poema (Bandeira, Kavafis, Montale, Eliot) ou o Baudelaire de as Flores do mal (nome dado ao primeiro poema do livro) são uma herança que rasuram a existência da voz poética que ecoa dos textos e, ao mesmo tempo, situam-na como fruto de uma origem indecidível, mas que guarda profunda afinidade com a poética rimbaudiana, dona também de uma força corrosiva a destruir os limites entre poesia e prosa e, por isso, estilhaçada, metonímica (CAMPOS, 2002, p.20).

A vida parece construir-se, de acordo com os poemas de $O$ roubo do silêncio, entre "a história que é remorso", como diz a epígrafe drummondiana, e o "Futuro [que] é agora", como sugere o título de um dos poemas do livro. Entre ambos, o presente sustenta tanto os deslocamentos do eu-poético no tempo e no espaço, quanto os deslocamentos do leitor, que percorre o périplo dos poemas não para buscar a compreensão dos mesmos, mas porque fundamentalmente percebe, como ensina João 
Alexandre Barbosa (1979, p.11), que a compreensão está na própria busca; esta, sempre o início de uma viagem; sempre uma partida; sempre um conjunto de jogadas; sempre o prazer do texto; sempre a renúncia ao pré-estabelecido.

A meu ver, o momento do livro em que se adensam o presente, a metalinguagem e o lirismo é aquele em que a poesia explode vigorosamente em som, tato e imagem. Trata-se do momento, quase final, em que o leitor se depara com o poema "Poesia a caminho". Este, segundo o percebo, configura-se como o ponto máximo das relações entre poesia, memória e silêncio mencionadas acima, que percorrem todos os textos do livro, dando-lhes unidade e mais do que isso, historicidade.

\section{Algumas considerações sobre "Poesia a caminho"}

A leitura do poema "Poesia a caminho" impõe que consideremos Siscar como um poeta crítico. Assim como acontece com outros poetas da modernidade e contemporaneidade (PERRONE-MOISÉS, 2003), não há como separar o poeta do crítico, sob pena de sacrificarmos a riqueza de uma poesia auto-reflexiva, metalinguística e sofisticada. Sob essa perspectiva de abordagem, o que se observa em "Poesia a caminho" é o crucial dilema do poeta (ou melhor, de sua consciência crítica) entre a comunicação poética, transitiva, aberta à significação, e a composição poética, fechada em si mesma, intransitiva, centrada em seu próprio significado (BARBOSA, 1974, p.22). De um lado, os segmentos da realidade que o poema aclara e intensifica, pelo uso das imagens do cotidiano; de outro, a própria realidade que o poema subverte para fundar um novo universo: o poético (BARBOSA, 1974, p.22). Situado na terceira parte do livro, denominada "Balões Brancos", entre os poemas "Sangue do meu sangue", que o antecede, e "O futuro é agora", que o sucede, o poema "Poesia a caminho" de um lado constitui-se segundo as tensões entre a sobrevivência do passado e o presente; de outro é um momento único do livro, porque nele se acentua a tensão entre prosa e poesia e, a meu ver, a poesia será a vitoriosa, por razões que veremos a seguir.

O poema que o antecede sugere o passado; o que vem depois, a (im)possibilidade do futuro pelo adensamento do agora. Desse modo, eu diria que 
"Poesia a caminho" é a consagração do instante poético no livro. Diferentemente dos outros poemas de $O$ roubo do silêncio, em que a memória e o silêncio jogam o lance de dados de uma poética rememorativa e densa, marcada pela pontuação da prosa e constantemente subvertida pela palavra poética, em "Poesia a caminho" não há pausas, reduzem-se as chances da prosa. A recuperação do tempo da narrativa,que é mencionada no poema, e como tentativa está presente no livro todo, é feita pelos recursos da poesia e, por isso, esse tempo narrativo é irrecuperável: não existe linearmente, mas obedece aos movimentos da memória; além disso, apesar de marcado pela poesia, o tempo, nesse poema, não é aquele em que há suspensão do instante; não é da ordem da pontualidade, não é o jorro de Octavio Paz, não é o ápice ou o gozo, mas o desejo de sua dilatação no tempo e no espaço; o tempo é o rito da "Poesia a caminho" e, como rito, dá lugar à ubiquidade da experiência e da memória em que insere também o "você" instaurado no texto.

Se pensado em termos de semiótica tensiva (FONTANILLE \& ZILBERBERG, 2001), o poema, apesar da intensidade a que a falta de pontuação obriga, é duração e extensidade, porque se sustenta pelo agônico fluxo das palavras, enunciadas sem pausa, vertiginosamente, embora esse fluxo encontre a resistência tanto do começo e do final do poema, quanto do silêncio no final de cada linha/verso. O movimento de fluxo e contrafluxo também pode ser observado em outras obras de Siscar, como aponta Célia Pedrosa, fazendo referência à figura do rio que não aparece em "Poesia a caminho", a não ser e exatamente, como fluxo, ou seja, ainda que não nomeado explicitamente no poema, há, em "Poesia a caminho", uma idéia de rio que garante "o fluxo e o transbordamento, e, simultaneamente, o refluxo e a contenção" (PEDROSA, 2004, p.1)

Entre o Se que inicia o texto e o ponto final que dele dá cabo está uma vida inteira - a possibilidade de manter-se sempre a caminho. Se nos outros poemas do livro a pontuação indica uma tensão entre a existência do verso ou não, uma interrupção mais marcada do fluxo, ou ainda, da travessia desse eu-poético, que parece ser sempre o mesmo em todos os poemas, em "Poesia a caminho", cada linha é mesmo verso, um verso que não surge apenas para "remunerar o defeito da língua", mas para lembrar ao poeta de que a poesia o obriga ao poema; sem pausas, cada linha de "Poesia a caminho" remunera, ainda, o lapso da lembrança, misturando som, sentido, imagens, de 
modo tão vívido, que o poeta, neste texto, maximiza a conversão da linguagem dos objetos da memória (a infância, a família, o cânone), em objeto da linguagem, ou seja, converte-os no próprio poema, marcado de metalinguagem[1]. Observemos, então, o poema (SISCAR, 2006, p.52):

\section{POESIA A CAMINHO}

Se apenas por um instante da ponta de um fio você se lembrasse você ao menos colocasse sob os olhos a cerimônia sem volta o rosto que não se evita se você se visse que agora escorre que aqui se deixa se você ao menos sentisse o inchaço das palavras significando sem saber a inflação dos corpos crescendo para onde não se estendem se não se apegasse à suposição convicta de próteses de conjunções de escoras para o coração de tubos para o poço escuro das artérias de líquidos azuis para as células se apenas por um instante morresse quanto amor o amorteceria fato o alcançaria poesia o realizaria contra seus desejos de fatos de comunidade de comunhão contra suas amostras de dor e medo de força e segredo e entretanto por ora apenas nessa ponta de rua mais uma esquina esses largos passos esses passos repetidos esses lugares reiterados recompondo o tempo da narrativa renovando fantasmas levantando suspeitas refazendo o suspense a trama a espera a esperança o adiamento o sonho do corpo imóvel como uma máquina bela e inútil sobre os escombros de poeira ou a gota prateada de suor descendo de suas narinas.

O poema surge na página como um bloco coeso, uma interferência regular e incisiva na folha branca, interferência esta que já é, desde sempre, roubo do silêncio, do silêncio fundador da página à espera da poesia que nela se instalará. São vinte e uma linhas, ou melhor, vinte e um versos carregados de uma dicção de prosa que serve de mote ao questionamento do modo de sere de estar do poema não apenas na página, mas também no espaço e no tempo de uma linguagem que guarda a historicidade e a herança da tradição poética da modernidade, sugerindo, além disso, a subversão dos traços memorialísticos que já vinham acompanhando os poemas do livro, porque há, na mudança de tom desse poema em relação aos anteriores, uma indicação de que a experiência da memória se converterá em experiência poética de forma mais contundente. 
"Poesia a caminho" é, então, uma tentativa de desconstrução da estrutura canônica do poema ao mesmo tempo que afirmação da onipresença da poesia como forma de pensamento (VALERY, 1999), experiência e relação com o mundo: conversão do vivido em verbo, por meio da alta carga de poeticidade que conduz ao inchaço das palavras, que escorrem tórridas pelo poema. $\mathrm{O}$ que se nota, em decorrência disso, é a inflação da escrita que se corporifica, estendendo-se em um fôlego único, já que inexistem sinais de pontuação que permitam uma pausa ao fluxo poético que vertiginosamente assola o poema, a não ser no início e no término de cada verso, como pontuamos. A avalanche das palavras fratura a continuidade do cotidiano e a pregnância da memória; é uma ruptura por meio da qual tanto o eu-poético quanto o "você" (que pode ser o leitor) podem experimentar a estesia (TEIXEIRA, 2004, p.228) pelo movimento da palavra que é também movimento dos corpos do sujeito poético e do você (corpos, coração, artérias, células, suor, narinas); ao experimentá-la, pela instauração de novas formas de significar, todo o cotidiano é re-semantizado, contrapondo-se aos desejos de fatos de comunidade / de comunhão contra as suas amostras de dor e medo de /força e segredo. Ou seja, mais do que fratura, a avalanche das palavras é a sustentação da poesia a caminho; é a chance da escapatória "é o movimento do corpo que se volta e vê o que não havia visto" (TEIXEIRA, 2004, p.229), experimenta alguma coisa que não havia experimentado. Pode ser, ainda, o movimento do corpo que, se aceitasse arriscar-se, veria o que não havia visto, ou veria aquilo que talvez não pudesse ver, sem correr o risco que a própria visão impõe; há, portanto, uma atmosfera órfica circulando pelo poema, sobretudo no início:

\footnotetext{
Se apenas por um instante da ponta de um fio você se lembrasse você ao menos colocasse sob os olhos a cerimônia sem volta o rosto que não se evita se você se visse que agora escorre que aqui se deixa se você ao menos sentisse o inchaço das palavras significando sem saber a inflação dos corpos crescendo para onde não se estendem se não se apegasse à suposição convicta de próteses de conjunções de escoras para o coração de tubos para o poço escuro das artérias de líquidos azuis para as células se apenas por um instante morresse
}

O olhar para trás de Orfeu seria a escrita e o livro; ambos são capazes de alimentar o olhar para o passado por meio da memória e, ao mesmo tempo, caracterizam 
a impossibilidade do retorno ao passado e de seu resgate absoluto; devemos nos lembrar de que Orfeu vê o in-visível: "a cerimônia sem volta o rosto que não se evita". O retorno órfico é também a cena da escritura (DETIENNE apud BRUNEL, 2003, p. 49), um desejo de restauração e de retorno a uma unidade perdida por meio de um olhar que é memória e, como memória, inscrição e linguagem. Podemos, então, pensar essa linguagem como plenitude (a poesia) e como falta (o poema). No poema, a poesia refaz o mundo, mas o universo poético é imperfeito porque é um espectro da realidade, portanto, é fratura e é imperfeição; é a marca da falta; é o poema e a possibilidade da escapatória.

O percurso da fratura à possibilidade da escapatória está espelhado na mudança dos tempos verbais ao longo do poema. Se o "você" instaurado no poema "aceitasse" o risco, o lance, a inevitabilidade do acaso, "poderia" encontrar, pelo caminho, "o amor" que "o amorteceria, o fato" [o agora] que "o alcançaria" e a poesia que "o realizaria", e essa realização mostrar-lhe-ia que a poesia está sempre à espreita, não é alheia à vida, mas uma possibilidade da existência, uma ponte entre o homem e o mundo, a travessia que os une, rio que escorre em gotas prateadas de suor e açude, sonho do corpo imóvel.

$\mathrm{O}$ caráter metalinguístico do texto leva-nos a imaginar que a máquina bela e inútil é o próprio poema, máquina de linguagem, corpo imóvel, mas carregado de pulsação vital, estabelecido na página, fruto da gota de suor prateado que desce das narinas do poeta; poema onde a festa dos sentidos, para além da audição, visão e tato, incorpora o olfato e transforma a poesia em encarnação "sobre os escombros de poeira”. Mas é preciso olhar com cuidado para esse corpo que, imóvel na página, articula a tensão entre o inteligível e o sensível, revelando um dinamismo intrínseco. Um exemplo disso são os jogos paronomásticos nada desprezíveis, que definem, em especial, assonâncias, rimas toantes e em eco: "agora/ escorre/ corpos/ escoras/ ora/ amostras"; "rosto/ poço"; "escuro/ tubo/ azuis"; "corpo/ como/ escombros"; "largos/ passos/ reiterados"; "convicta/ conjunção"; “medo/ segredo". Também cabe ressaltar a presença metonímica em "amor - amorteceria"; "esperaesperança"; "comunidade-comunhão" e a reiteração da idéia de retorno pela sequência de vocábulos iniciados por re - "reiterados/ recompondo/ refazendo/ repetir". Esses 
aspectos intensificam a circularidade do texto, o seu caráter autotélico, reforçado pela reincidência dos verbos no subjuntivo até "se morresse"; a partir daí, como se a morte, mais como transcendência do que como fim, pudesse viabilizar uma série de outras possibilidades para o "você” instaurado no poema, dá-se início a uma sequência de verbos no futuro do pretérito que, posteriormente, são substituídos por outros verbos no gerúndio, também sugestivos da circularidade, inclusive pela discreta nasalização que os acompanha.

Algumas imagens e expressões também merecem destaque porque sublinham a extrema poeticidade do texto: "cerimônia sem volta/ inchaço das palavras/ inflação dos corpos/ próteses de conjunções/ coração de tubos/ tubos para o poço escuro/ artérias de líquidos azuis/ gota prateada de suor". Dentre essas, a mais bela é, sem dúvida, "escoras para o coração", não apenas pelo caráter metonímico, e pela imagem que revela, dentro do CORAção, as esCORAs; mas também porque parecem ser essas "próteses de conjunções de escoras" que impedem o "você" do poema a uma entrega. A entrega é a garantia de sobrevivência da poesia a caminho, a entrega é o que prolonga o caminho da palavra poética circulante no texto. A partir da menção de "inflação dos corpos" há um movimento de interiorização sugerido pelo caminho das palavras para o corpo, deste para o coração, artérias e células; também as imagens corroboram essa hipótese: "tubos/ poço/ artérias azuis/ célula":

estendem se não se apegasse à suposição convicta de próteses de conjunções de escoras para o coração de tubos para o poço escuro das artérias de líquidos azuis para as células se apenas por um instante morresse

São marcadamente poéticas as gradações "amor-amorteceria; "fato- alcançaria"; "poesia- realizaria"; ou ainda, "refazendo o suspense a trama a espera / a esperança o adiamento/ o sonho do corpo imóvel" que reforçam, em conjunto com outros aspectos, a idéia da poesia a caminho com a qual o poeta se depara nas ruas, esquinas e passos que mais do que repetir, reinventa para recompor o tempo de sua própria narrativa gauche, porque poética com acentos drummondianos, e para lidar com seus 
mortos por meio de um trabalho de luto que os transforma em espectros. Vale destacar que o espectro não é; o espectro é o que poderia ter sido em potência ou, simplesmente, aquilo que a memória pode conceder a ele.

As lembranças, os lugares reiterados, enfim todas as marcas do trabalho da memória revelam, não só nesse poema, mas no livro $O$ roubo do silêncio, de modo geral, um esforço do poeta para lidar com aquilo que herdou da vida e da poesia, "experiência vivida e lida" (PEDROSA, 2004, p. 2). A herança não é recebida passivamente no livro de Marcos Siscar, mas articula, pelo trabalho de luto, a sobrevivência daquilo que é herdado, usando-o de modo ativo e inventivo, tornando-o possibilidade de luta contra o acaso, contra o tempo, contra o esquecimento; usando-o como bagagem para a travessia. $\mathrm{O}$ trabalho com a experiência vivida e lida indica que $\mathrm{o}$ reconhecimento é uma possibilidade de ser da memória, à medida em que promove uma abertura para a vida dada pela relação entre a vida mesmo e o vivido (SISCAR 2000, p.163). Nesse sentido, seria importante considerar que talvez haja, no reconhecimento e no trabalho pela sobrevivência, uma subversão do vivido que emerge da obra do poeta destituído de seu corpo original, porém reencarnado, feito carne novamente, na corporalidade da palavra poética.

\section{À guisa de conclusão}

Diante da opacidade do poema, aparentemente caótico, deve-se procurar formas que sejam dotadas de sentido, algo que permita converter o caos inaugural da primeira leitura em cosmos. Assim sendo, a leitura é uma tomada de posição da percepção, é uma tentativa de tomar posse do poema por meio da organização de suas reiterações e identificação daquilo que é contraponto (TEIXEIRA, 2004, p.225); a leitura aqui apresentada rapidamente é apenas uma possibilidade de determinada percepção. É uma tentativa de destacar que o que se vê no poema configura-se na relação do corpo com o mundo poético revelado; mundo este que se impregna no leitor a partir dos tentáculos da inevitável palavra poética, que autoriza a reconsideração de nossos códigos e verdades. 
Por isso, o poema é arte; melhor dizendo, a arte, como ensinou o poeta Jorge Luís Borges, "acontece cada vez que lemos um poema” (BORGES, 2000, p.15). Seria bom se nos lembrássemos sempre, e isso nos ensina a poética de Siscar, de que o poema, como ocasião para a poesia, revela, sobretudo, e antes de qualquer outra coisa, o roubo do silêncio e algumas razões para a poesia a caminho; razões dessa máquina de linguagem constantemente repensada, chamada poema, que em vão tentamos recolher dos escombros da tradição e dos nossos próprios.

\section{REFERÊNCIAS}

BARBOSA, J. A. Um cosmonauta do significante: navegar é preciso. In: CAMPOS, H. de. Signacia quase coelum, signância quase céu. São Paulo: Perspectiva, 1979. p.1120 .

A Imitação da forma: uma leitura de João Cabral de Melo Neto. São Paulo: Duas Cidades, 1975. p.9-46.

Exercícios de Definição. In: A metáfora crítica. São Paulo: Perspectiva, 1974.

BORGES, J. L. O enigma da poesia. In: Esse ofício do Verso. São Paulo: Companhia das Letras, 2000. p 9-28.

CAMPOS, A. de. Alguns Rimbauds. In: CAMPOS, A. de. (Org.). Rimbaud Livre. São Paulo: Perspectiva, 2002. p.11-20.

BRUNEL, P. As vocações de Orfeu. In: BRICOUT, B. (Org.). O Olhar de Orfeu: Os mitos literários do ocidente. Tradução: Lelita Oliveira Benoit. São Paulo: Companhia das Letras, 2003. p.39-62.

GREIMAS, A. J. Da imperfeição. Tradução: Ana Cláudia Oliveira. São Paulo: Hacker, 2002.

LEMOS, M. Algumas paisagens: a poesia de Regis Bonvicino e Marcos Siscar. Anais do XI Congresso Internacional da Abralic - Tessituras, Interações, Convergências. São Paulo: USP/ABRALIC, 2008. Disponível em www.abralic.org.br/ Data de acesso: 20/03/2009.

ORLANDI, E. P. As formas do silêncio. Campinas: UNICAMP, 2007.

PEDROSA, C. Versos que correm entre a margem e o fluxo, a linha e o corte.

Resenha. Revista Agulha. Disponível em www.revista.agulha,nom.br/celiapedrosa.html Data de acesso: 20/03/2009.

SISCAR, M. O roubo do silêncio. Rio de Janeiro: 7Letras, 2006.

A paixão ingrata. In: NASCIMENTO, E; GLENADEL, P. (Org.). Em torno de Jacques Derrida. Rio de Janeiro: CNPq/7Letras, 2000. p.160-187. 
TEIXEIRA, L. Station Bourse: o que os olhos não viram. In: MARCHEZAN, R. C.; CORTINA, A.Razões e Sensibilidades: a semiótica em foco. Araraquara: UNESP/ Cultura Acadêmica/ Laboratório Editorial da Faculdade de Ciências e Letras, 2004, p. 221-247.

VALERY, P. Poesia e pensamento abstrato. In: Variedades São Paulo: Iluminuras, 1999.

[1] A respeito dessa conversão cf. BARBOSA, J. A. A imitação da forma: uma leitura de João Cabral de Melo Neto. São Paulo: Duas Cidades, 1975. 